\title{
Shear-wave splitting beforeand after the 1999 Xiuyan earthquake in Liaoning, China*
}

\author{
TAI Ling-xue ${ }^{1)}$ (太龄雪) GAO Yuan ${ }^{1), *}$ (高 原) CAO Feng-juan ${ }^{2)}$ (曹凤娟) \\ SHI Yu-tao ${ }^{1)}$ (石玉涛) WU Jing ${ }^{1,3)}$ (吴晶) JIAO Ming-ruo ${ }^{2)}$ (焦明若) \\ 1) Institute of Earthquake Science, China Earthquake Administration, Beijing 100036, China \\ 2) Earthquake Administration of Liaoning Province, Shenyang 110031, China \\ 3) Earthquake Administration of Jiangsu Province, Nanjing 210014, China
}

\begin{abstract}
Using seismic waveform data recorded at station YK (Yingkou) of Liaoning Telemetry Digital Seismic Network, this paper studied the characteristics of shear-wave splitting before and after the Xiuyan $M_{\mathrm{S}} 5.9\left(M_{\mathrm{L}} 5.3\right)$ earthquake in November 29, 1999 with SAM method. The results show that the predominant polarizations of fast shear-waves at $\mathrm{YK}$ is in direction of ENE-WSW, consistent with the direction of regional principal compressive stress and also consistent with the direction of the regional tectonic stress field in North China; time-delays increasing before Xiuyan earthquake may shows accumulation of stress before earthquake. The predominant polarizations of fast shear-waves at YK are also related to the spatial distribution of small earthquakes and correlate with the fault strike. The histogram of monthly average polarizations of fast shear-waves shows that polarizations of fast shear-waves also seems to change from two months before the earthquake, but it still needs more data for verification.
\end{abstract}

Key words: Xiuyan earthquake; shear-wave splitting; polarization; time delay CLC number: P $315.3^{+} 1 \quad$ Document code: A

\section{Introduction}

Lots of researches have proved that seismic anisotropy exists in different depths in the Earth's interior. There are several causations of seismic anisotropy in the crust, but the most common interpretation is stress-aligned fluid-saturated grain-boundary EDA (Extensive-dilatancy Anisotropy) cracks (Crampin and Atkinson, 1985). Shear-waves split into fast shear-waves and slow shear-waves when traveling through EDA cracks. The predominant polarization of fast shear-waves is consistent with strike of cracks, and also consistent with the direction of regional principal compressive stress; time delays of slow shear-waves reflect anisotropic degree. Therefore shear wave splitting can be applied to studying the feature of crust media, variation of crustal stress (GAO et al, 1995; SHI et al, 2006; WU et al, 2007) and inhomogeneity of regional distribution of fault and anisotropy through comparison and analysis of geologic and geophysical observation data. It can also be helpful for earthquake prediction by studying variation of shear-wave splitting parameters before and after earthquake (GAO et al, 1996; Crampin, 2001; Crampin et al,

\footnotetext{
* Received 2007-10-12; accepted in revised form 2008-06-03.

Foundation item: Basis and Special Research Foundation, Institute of Earthquake Science, China Earthquake Administration (2007-24).

^ Author for correspondence: gaoyuan@seis.ac.cn
} 
2003a). Recent research showed that time delays of slow shear-waves can reflect fluid pressure variation in cracks (Tang et al, 2005). Research on shear-wave splitting around the Atotsugawa fault in Japan showed that the angle between the direction of local maximum horizontal compressive stress and the fault strike increased with increase of distance between stations and fault (Mizuno et al, 2005). That is to say, with the distance increase between station and fault, the influence of fault on the local principal compressive stress under station becomes less, and the direction of local principal compressive stress further tends to that of the regional stress field.

On November 11, 1999, at 12:10 (Beijing Time), an earthquake, Xiuyan earthquake, occurred in boundary zone of Pianling town of Xiuyan county and Gushan town of Haicheng county, Liaoning Province, China. According to the observation of China Earthquake Network Center, the epicentral location was at $\left(40.53^{\circ} \mathrm{N}, 123.15^{\circ} \mathrm{E}\right)$, with $M_{\mathrm{S}} 5.9\left(M_{\mathrm{L}} 5.3\right)$ and focal depth at $7 \mathrm{~km}$. While Liaoning Seismic Network measured that, the epicentral location was at $\left(40.53^{\circ} \mathrm{N}\right.$, $\left.123.02^{\circ} \mathrm{E}\right)$, with $M_{\mathrm{S}} 5.6\left(M_{\mathrm{L}} 5.9\right)$ and focal depth at $10 \mathrm{~km}$. It is another earthquake which has been predicted successfully and mitigated disaster since Haicheng M7.3 earthquake in Liaoning (JIANG and TONG, 2001). According to observation data, Earthquake Administration of Liaoning Province packed up the Xiuyan earthquake sequence, which includes not only the foreshock sequence but also the long time aftershock sequence. It is an integrated earthquake sequence including foreshock, main shock and aftershock (LAN et al, 2006). Based on the seismic data recorded at station YK (Yingkou) of Liaoning Telemetry Digital Seismic Network from June 1999 to December 2000, (GAO et al, 2004), this paper studied seismic anisotropy in the crust and discussed the variation characteristics of anisotropic parameters with the SAM method.

\section{Background}

Xiuyan-Haicheng area is at northeast of Sino-Korean mesa, at the connection of Jiaoliao massif and North China block. From the neotectonic movement, it is in Liaodong uplift, at the connection of Liaodong uplift and Xialiaohe basin. The rising speed of local crust has shown the unceasing acceleration characteristic since Neogene, and the diastrophism is obviously active in recent years (WAN, 2000; GAO and ZHONG, 2000). Because present tectonic movement shows that Xialiaohe basin is tensile depression and both sides are uplift. Stress is especially easy to concentrate on the active fault striking NE at boundary between basin and uplift, and the intersection zone with the faults striking NW or E-W become somewhere stress heavily concentrate and release, it is also the concentration zone of earthquakes in Liaoning Province (MA et al, 1989). Earthquakes are frequently in Xiuyan-Haicheng area, where is the most active earthquake zone in Liaoning Province. Earthquakes are very dense in this zone especially during Haicheng earthquake and Xiuyan earthquake. Xiuyan earthquake is another strong earthquake more than 20 years later after Haicheng earthquake, of which the triggering tectonic is Haichenghe fault striking NW, which is closely related to the earthquake triggering tectonic of Haicheng earthquake (WAN, 2000).

Around the epicenter of Xiuyan earthquake there are three main faults, which are respectively Haicheng-Yingkou fault striking NE, Jinzhou fault striking NNE and Haichenghe fault striking NW (Figure 1). Haicheng-Yingkou fault and Jinzhou fault belong to the largest fault in east China zone, i.e. Tanlu fault zone. However Haichenghe fault is the earthquake triggering tectonic of the 1975 Haicheng earthquake and the 1999 Xiuyan earthquake. Haichenghe fault, striking to $320^{\circ}$ (from North), is a developing one which originates from Gaokan of Yingkou, passes towards SE through Pianling of Xiuyan and extends to city Donggang (LÜ et al, 2004). 


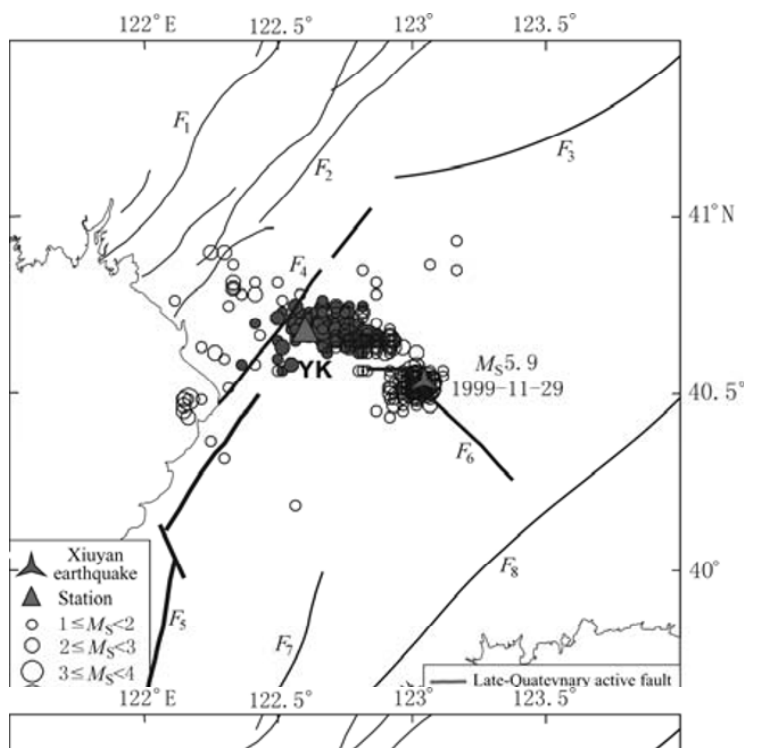

Figure 1 Location of the station YK and earthquakes within $60 \mathrm{~km}$

Solid circles are earthquakes in shear-wave window, and open circles are earthquakes out of shear-wave window but less than $60 \mathrm{~km}$ to station YK (June 1999 to December 2000). $F_{1}$. Shuangtaizi fault; $F_{2}$. Erjiegou fault; $F_{3}$. Taizihe fault; $F_{4}$. Haicheng-Yingkou fault; $F_{5}$. Jinzhou fault; $F_{6}$. Haichenghe fault; $F_{7}$ Biliuhe fault; $F_{8}$ Zhuanghe fault
Liaoning Telemetry Digital Seismic Network (LTDSN) is composed of Shenyang center station and 15 telemetry seismograph stations (JIANG and TONG, 2001). It ran tentatively from June 1999 and formally from September 20, 1999. Its monitoring ability is $M_{\mathrm{L}} \geq 2.0$ earthquakes to south of Liaoning, i.e., Xiuyan-Haicheng area (LÜ et al, 2004). This study adopts seismic waveform data after June 1999 at station YK (Yingkou). Most stations of LTDSN are equipped with JCZ-1 short-period seismometers, but station $\mathrm{YK}$ is equipped with FBS-3 broadband seismometer, with frequency band of $0.05 \sim 20 \mathrm{~Hz}$ and sampling rate of $50 \mathrm{~Hz}$.

\section{Method and data processing}

\subsection{Method}

Seismic shear-waves split into two waves when traveling through EDA cracks, the first arriving wave is fast shear-wave, the second arriving wave is slow shear-wave, and there is time delay

between fast shear-wave and slow shear-wave. Time delays reflect anisotropic degree of the medium, and they are influenced by the physical features of the cracks and the characteristic of the fluid-saturated. The two shear-waves have the largest amplitude at the nearly vertical direction respectively. When shear-wave encounters ground surface, total reflection will occur if the incident angle is larger than the critical angle. In order to avoid the occurrence of total reflection, it is necessary to select the data within shear-wave window. Shear-wave window is about $35^{\circ}$ in Poisson medium (Poisson's ratio is 0.25 ), but at the effect of superficial sedimentary layer, shear-wave window can be widen to $45^{\circ}$ (Crampin and Peacock, 2005).

This study used shear-wave splitting system analysis method, namely, SAM method (GAO et $a l, 2004)$, which was put forward based on the analysis method of correlation function. It includes mainly three aspects, i.e., calculation of cross-correlation function, elimination of time delay and check of polarization analysis, which is of self-examination function. SAM method software has been updated recently for convenient use ${ }^{\mathbb{1}}$.

The main purpose of shear-wave splitting analysis is to separate the fast shear-wave and slow shear-wave from the ground surface record. Because the fast shear-wave and slow shear-wave originate from the same wave source, the two shear-waves should be correlative after the elimination of time delay (GAO and ZHENG, 1994). Calculation of cross-correlation function is to rotate

\footnotetext{
${ }^{(1)}$ GAO Yuan, SHI Yu-tao, LIANG Wei, et al. 2008. Systematic analysis method of shear-wave splitting SAM (2008): Software system [J]. Earthquake Research in China, (accepted) (in Chinese).
} 
the two horizontal components and get two new components. The rotation angle $\alpha$ begins from north, and rotates clockwise from $0^{\circ}$ to $180^{\circ}$ with the step length $1^{\circ}$; time delay $\Delta t$ changes from $-0.1 \mathrm{~s}$ to $0.1 \mathrm{~s}$ with the step length $0.02 \mathrm{~s}$. When the correlation coefficient of the two waves is maximum, the angle $\alpha$ is the polarization of fast shear-wave and $\Delta t$ is the time delay of slow shear-wave. Then the effect of time delay is eliminated according to the calculation of cross-correlation function. Finally, the polarization analysis of the two horizontal components is checked before and after elimination of time delay. According to GAO and ZHENG (1994), if the polarization diagram after the elimination of time delay shows linear feature, the result is reliable; otherwise we should calculate the parameters of shear-wave splitting again, and checkout the result again.

\subsection{Data processing}

Here are several examples to show the data processing. Figure 2 shows four seismic waveforms recorded at station YK of LTDSN. They are all three-component records. We selected 40 sampling data from the original three-component of seismic waveforms and calculated cross-correlation function. Figure 3 shows the calculation result of cross-correlation function.
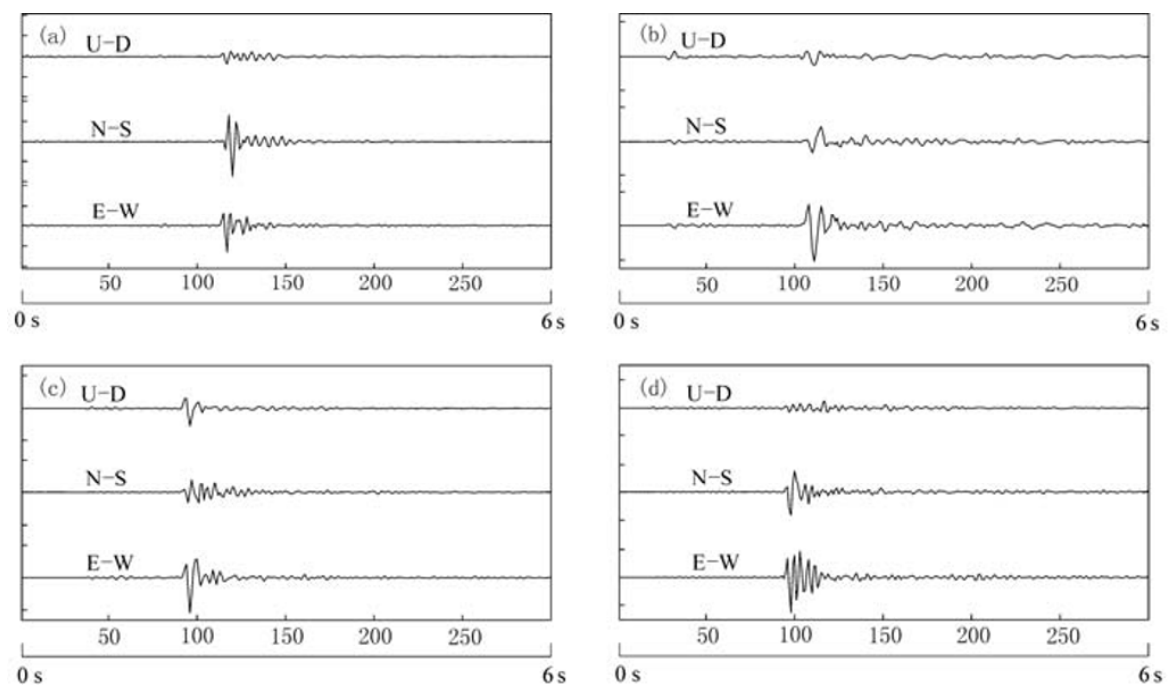

Figure 2 Three-component seismic waveforms recorded at station YK

(a) Seismic waveform of an $M_{\mathrm{L}} 2.0$ earthquake on August 19, 1999, with focal depth of $16 \mathrm{~km}$ and epicentral distance of $8.98 \mathrm{~km}$; (b) Seismic waveform of an $M_{\mathrm{L}} 3.1$ earthquake on September 6, 1999, with focal depth 6 $\mathrm{km}$ and epicentral distance $5.13 \mathrm{~km}$; (c) Seismic waveform of an $M_{\mathrm{L}} 2.0$ earthquake on December 25, 1999, with focal depth $10 \mathrm{~km}$ and epicentral distance $5.21 \mathrm{~km}$; (d) Seismic waveform of an $M_{\mathrm{L}} 2.4$ earthquake on January 7, 2000, with focal depth $12 \mathrm{~km}$ and epicentral distance $0.44 \mathrm{~km}$. Abscissa denotes sample number, sampling rate is $50 \mathrm{~Hz}$

Figure 4 shows shear-wave polarization diagram of N-S component and E-W component, which have not been eliminated time delay, the N-S component shear-waveform, and E-W component shear-waveform, respectively. The track of the particle movement of the two horizontal components is non-linear. According to the calculation of cross-correlation function, we rotate the two horizontal components to angle $\alpha$, get fast and slow shear-waves, and then the slow shear-wave is moved forward with $\Delta t$ to eliminate the effect of time delay, that is elimination of time delay. If the polarization diagram after waveform rotation and elimination of time delay shows linear feature (Figure 5), the calculation result is reliable. For the influence of instrument, 

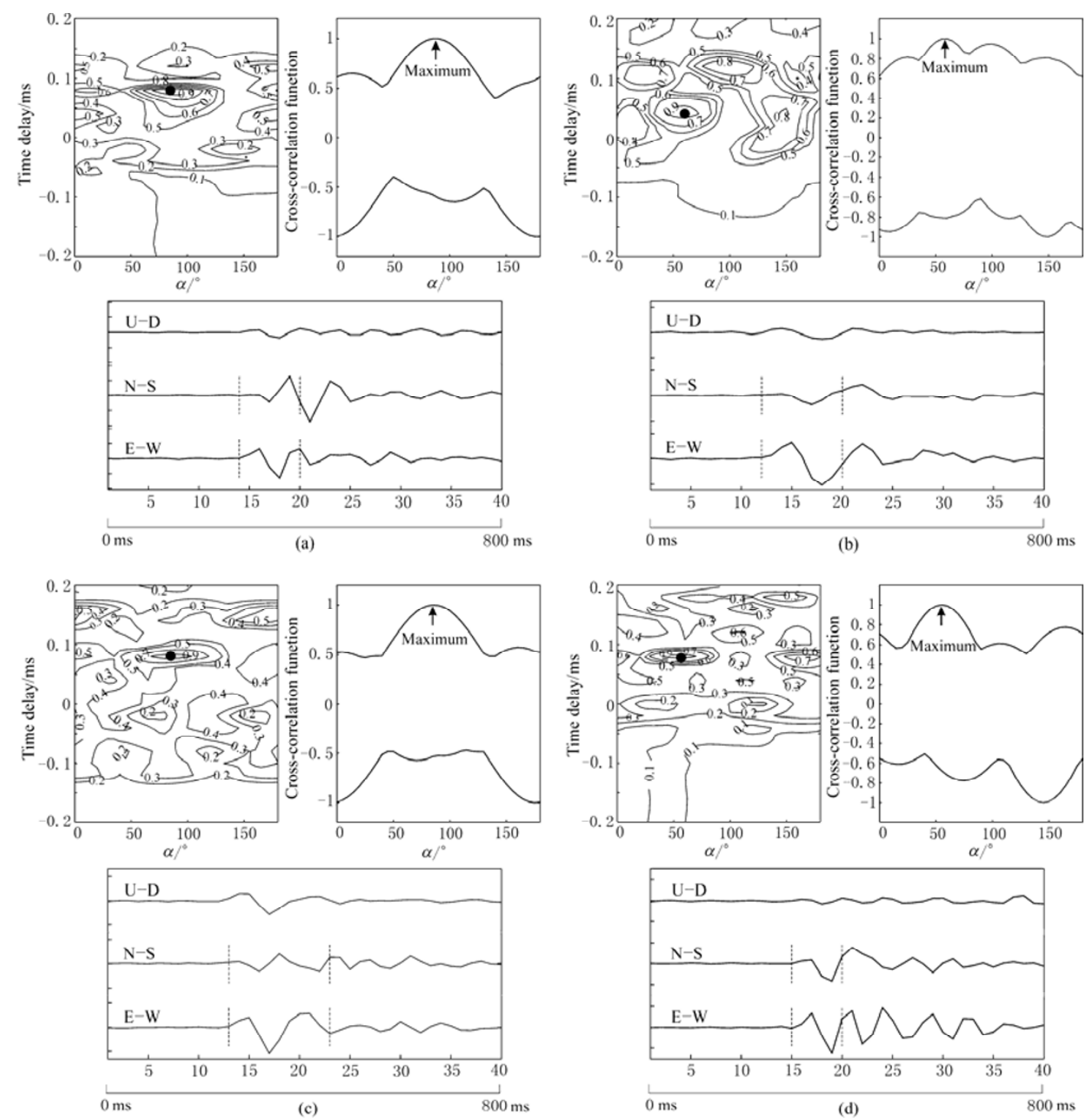

Figure 3 The calculation result of cross-correlation function

(a) Polarization of fast shear-wave is $85^{\circ}$ and time delay is $0.08 \mathrm{~s}$; (b) Polarization of fast shear-wave is $60^{\circ}$ and time delay is $0.04 \mathrm{~s}$; (c) Polarization of fast shear-wave is $85^{\circ}$ and time delay is $0.04 \mathrm{~s}$; (d) Polarization of fast shear-wave is $55^{\circ}$ and time delay is $0.08 \mathrm{~s}$. (a), (b), (c) and (d) correspond to the four earthquakes (a), (b), (c) and (d) showed in Figure 2, respectively. On each sub-figure, the top left plot gives isolines of cross-correlation with different polarizations and time delays, the black solid circle marks position of the highest cross-correlation function value. Top right shows distribution of the maximum and the minimum values of cross-correlation function. Lower plot displays the three-component shear-waveform, with abscissa denoting the number of samples

observational environment and waveform etc., the calculation result of cross-correlation function may be different from the final result. However, the calculation result of cross-correlation function can indicate some effective information. In most cases, calculation, elimination and checking need be repeated.

Several peculiar waveforms were found in the data processing, which cannot be judged in the 
reliability of the calculation result simply by the linearity of polarization diagram. Two such waveforms recorded at station YK are showed here. Figures 6 to 9 are diagrams of the three-component seismic waveform, calculation result of cross-correlation function, horizontal shear-wave polarization and check of polarization analysis, respectively.
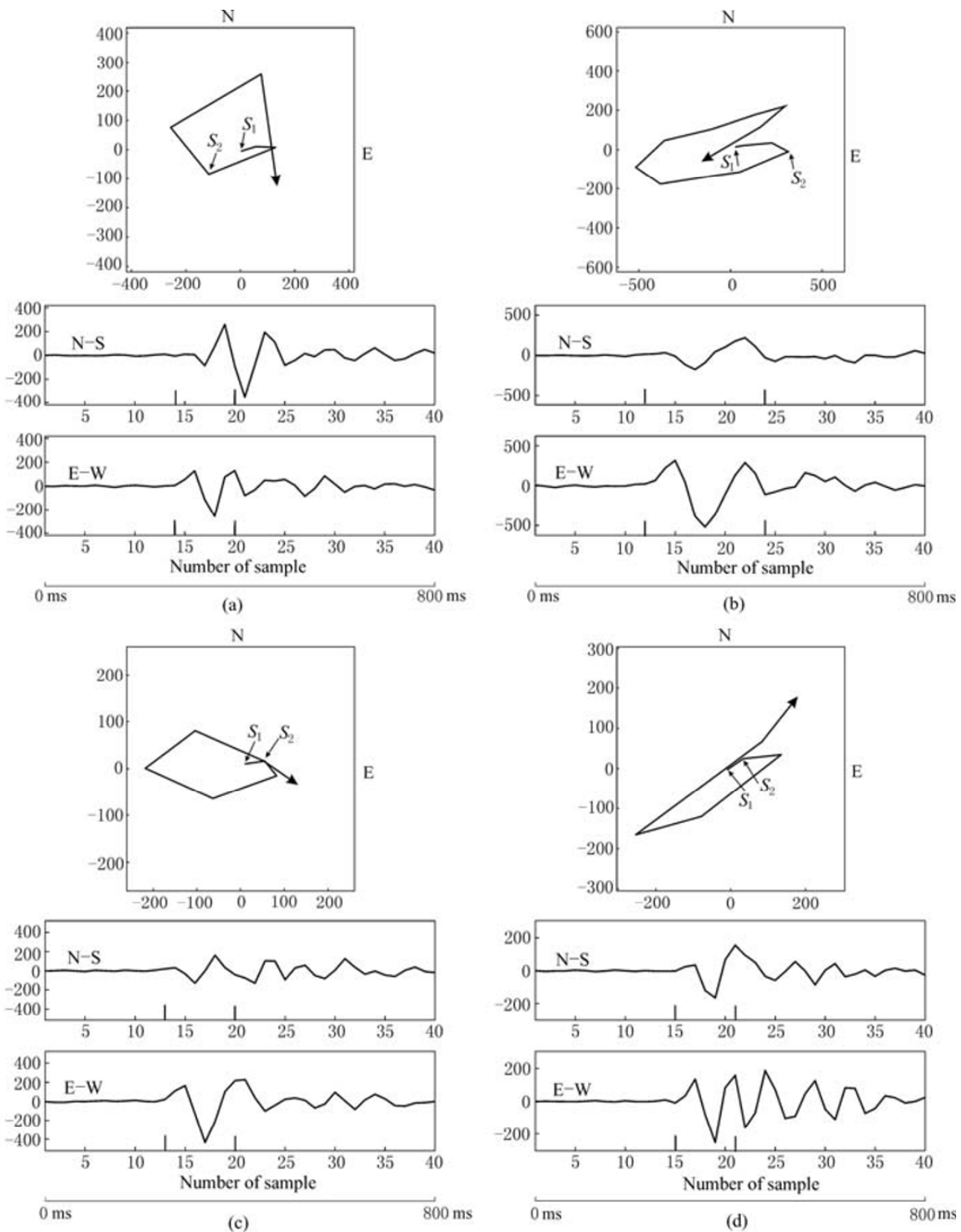

Figure 4 Demonstration of horizontal shear-wave polarization

(a), (b), (c) and (d) correspond to the four earthquakes (a), (b), (c) and (d) in Figure 3, respectively. On each sub-figure, the upper plot shows the trail of shear-wave particle motion; the middle is N-S component shear-waveform, and the lower is E-W component. $S_{1}$ and $S_{2}$ indicate the start position of fast and slow shear-wave, respectively

It was shown in the diagram of check of polarization analysis that the track of particle movement of fast and slow shear-waves does not show any rule or linear feature, though wave- 
form rotation and elimination of time delays have been done. This phenomenon mainly originates from the different frequency between the fast and slow shear-waves, and it depends more on the polarization diagram and waveform rotation to analyze the result in this case. It is also one of the reasons that GAO and ZHENG (1994) and SAM method (GAO et al, 2004) emphasize to check the result with polarization diagram. The polarization feature is an important content in SAM method put forward by GAO et al (2004) (see GAO et al, 1995, 1996).
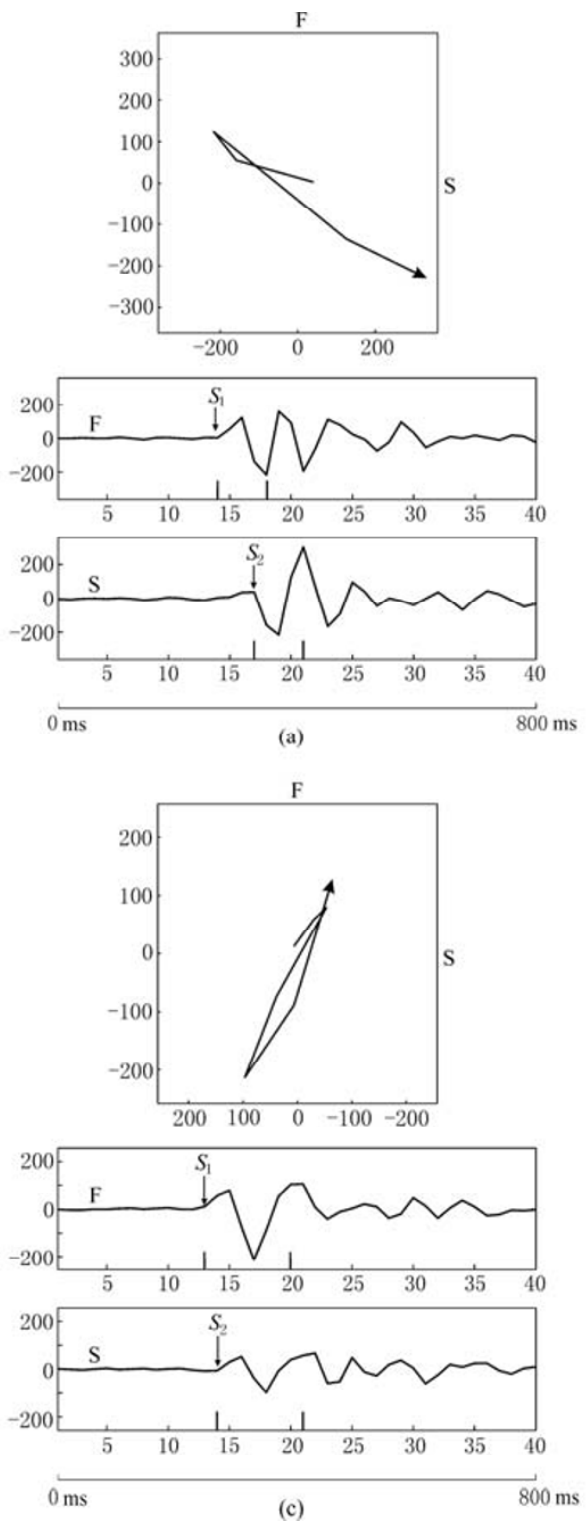
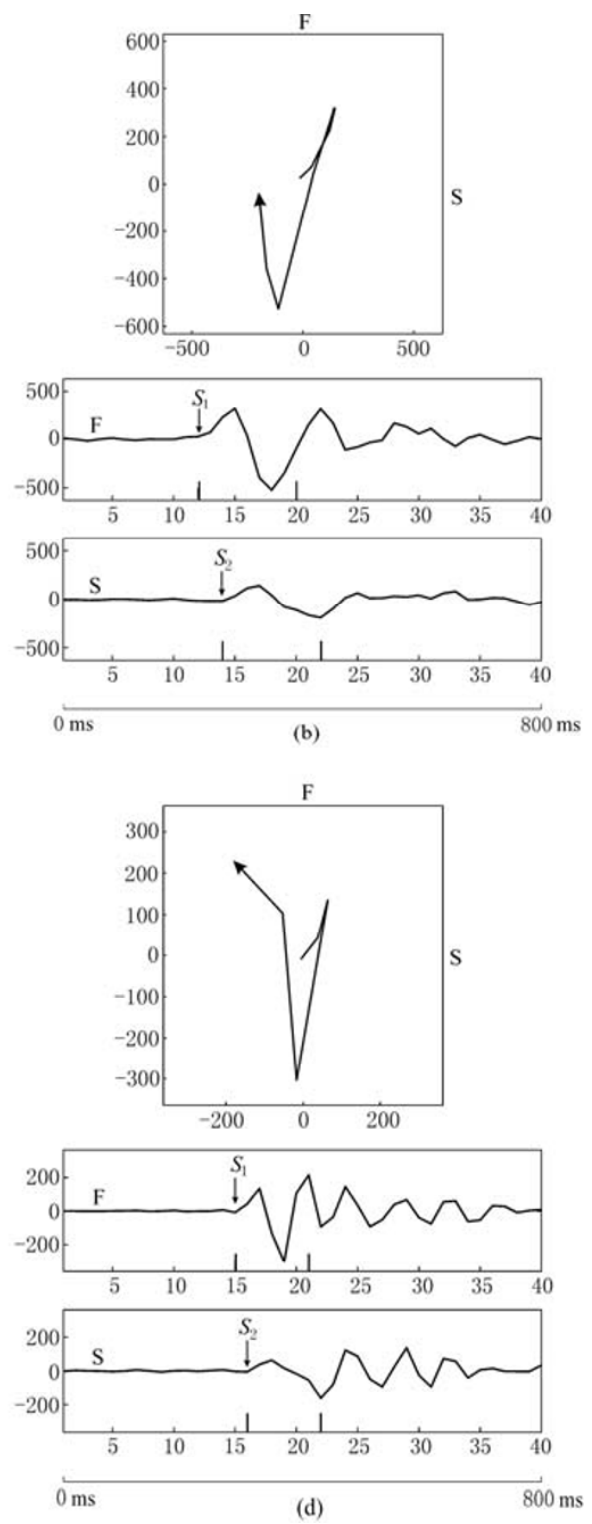

Figure 5 Check of polarization analysis

(a) Polarization of fast shear-wave is $70^{\circ}$ and time delay is $0.06 \mathrm{~s}$; (b) Polarization of fast shear-wave is $85^{\circ}$ and time delay is $0.04 \mathrm{~s}$; (c) Polarization of fast shear-wave is $85^{\circ}$ and time delay is $0.02 \mathrm{~s}$; (d) Polarization of fast shear-wave is $60^{\circ}$ and time delay is $0.02 \mathrm{~s}$. (a), (b), (c) and (d) correspond to the four earthquakes (a), (b), (c) and (d) in Figure 4, respectively. On each sub-figure, the upper shows the shear-wave polarization with time delay effect being eliminated. The middle is fast shear-waveform and the lower is slow shear-waveform. $S_{1}$ and $S_{2}$ indicate the start position of fast and slow shear-wave respectively 

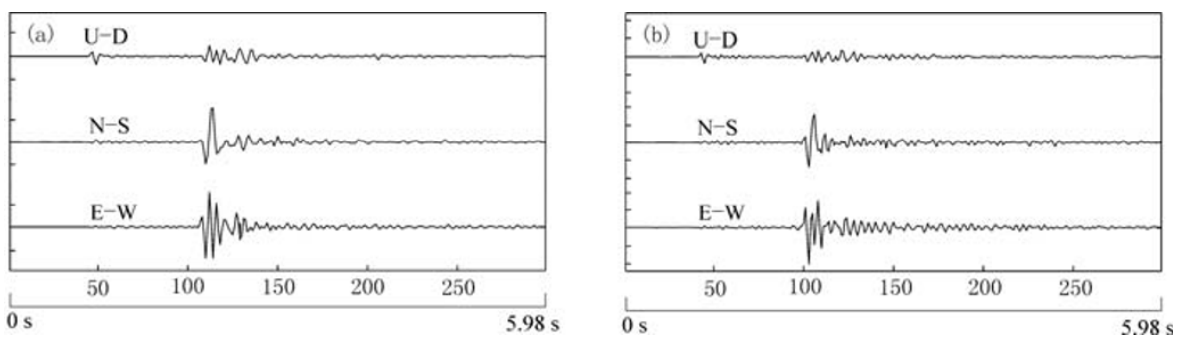

Figure 6 Two earthquake records with peculiar three-component waveform

(a) Seismic waveform of an $M_{\mathrm{L}} 1.8$ earthquake on September 9, 1999, with focal depth of $7 \mathrm{~km}$ and epicentral distance of $0.9 \mathrm{~km}$; (b) Seismic waveform of an $M_{\mathrm{L}} 1.6$ earthquake on October 14, 1999, with focal depth 9 $\mathrm{km}$ and epicentral distance $4.2 \mathrm{~km}$
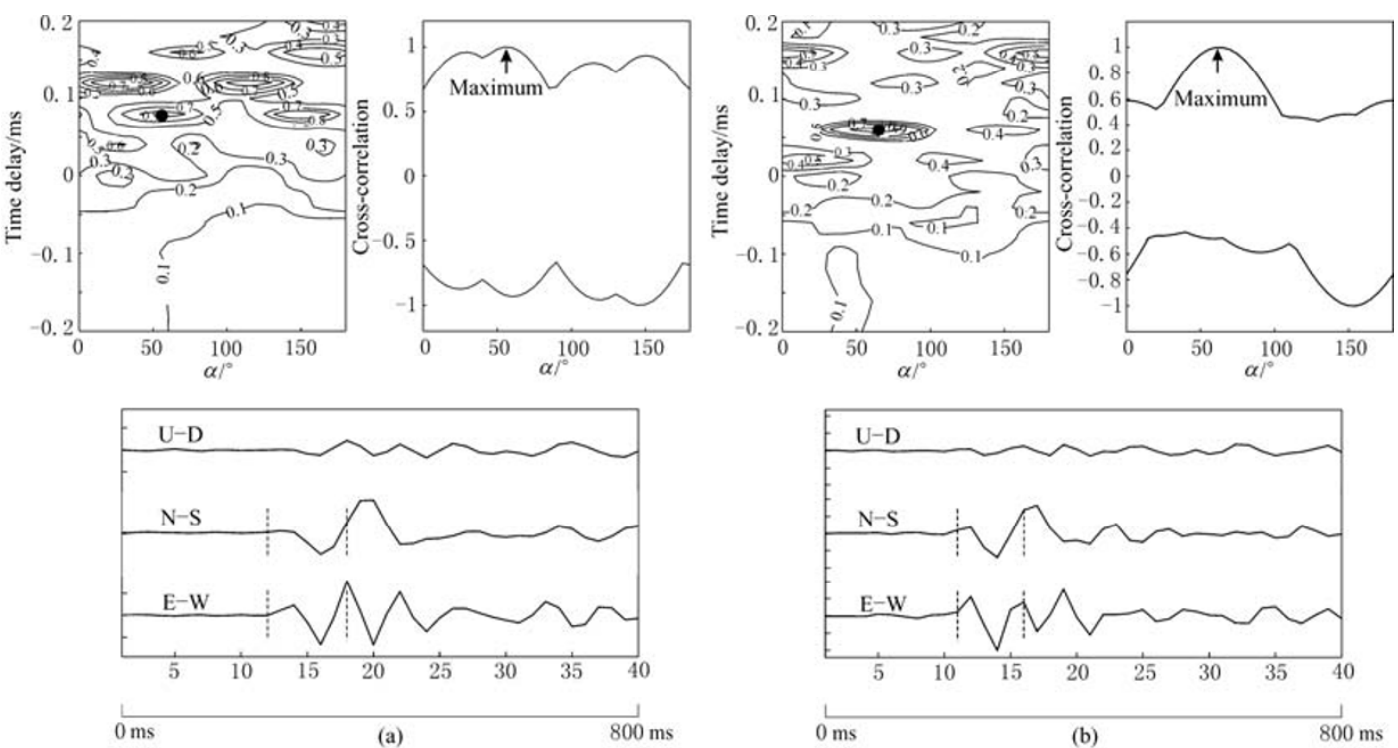

Figure 7 Calculated cross-correlation function for the two earthquakes with peculiar waveform (a) Polarization of fast shear-wave is $55^{\circ}$ and time delay is $0.08 \mathrm{~s}$; (b) Polarization of fast shear-wave is $65^{\circ}$ and time delay is $0.06 \mathrm{~s}$. (a) and (b) correspond to the two earthquakes (a) and (b) in Figure 6, respectively. Other explanations are the same as that in Figure 3

\section{Data analysis}

This paper analyzed the seismic waveform data recorded at station YK from June 1999 to December 2000 with SAM method ${ }^{\mathbb{}}($ GAO et al, 2004). In all 143 data records available within shear-wave window (incident angle $\leq 45^{\circ}$ ), focal depths of 12 records are unknown. Analyzing the 131 data with focal depth at station YK, the focal depths of all earthquakes distribute between $5 \mathrm{~km}$ and $16 \mathrm{~km}$ and average focal depth is at $11.3 \mathrm{~km}$, of which the focal depths of 120 records are between $8 \mathrm{~km}$ and $16 \mathrm{~km}$, accounting for $92 \%$ of whole earthquakes with focal depths. Based on the result of SHI et al (2006), we also included these 12 records without focal depths but epicentral distance less than $8 \mathrm{~km}$ as supplement data (Table 1).

\footnotetext{
${ }^{(1)}$ GAO Yuan, SHI Yu-tao, LIANG Wei, et al. 2008. Systematic analysis method of shear-wave splitting SAM (2008): software system [J]. Earthquake Research in China, (accepted) (in Chinese).
} 

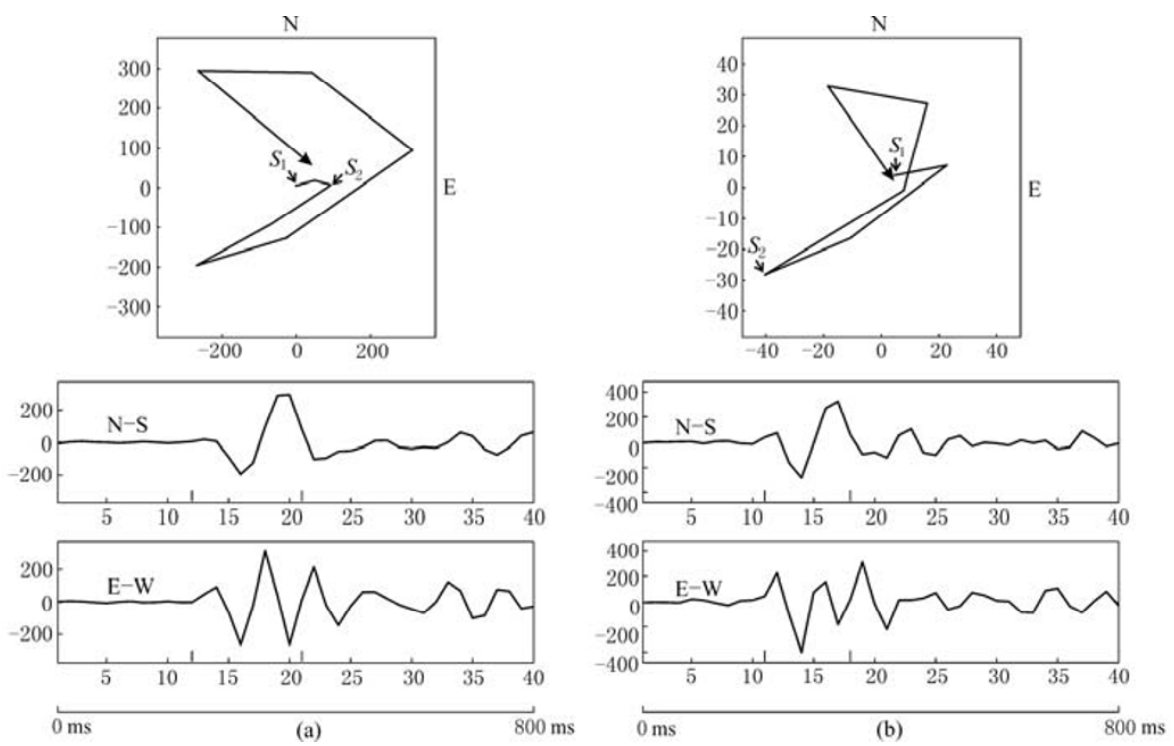

Figure 8 Horizontals shear-wave polarization of the two peculiar waveforms

(a) and (b) correspond to the two earthquakes (a) and (b) in Figure 6. Other explanations are the same as that in Figure 4
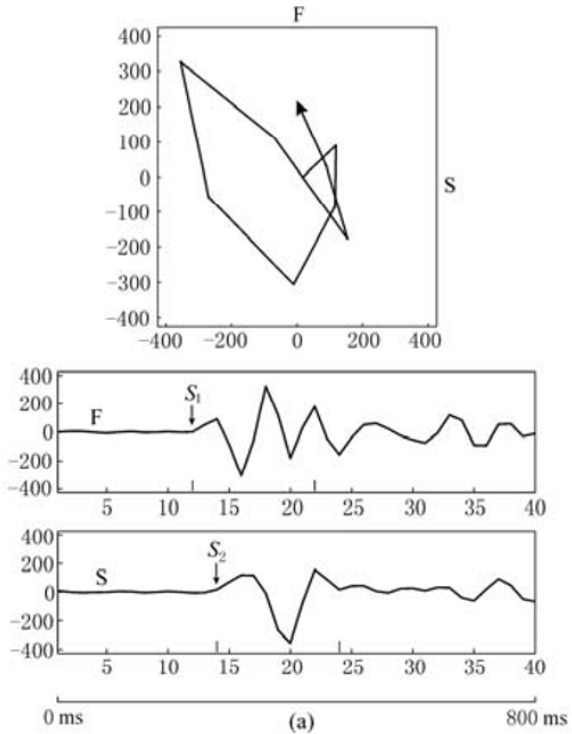
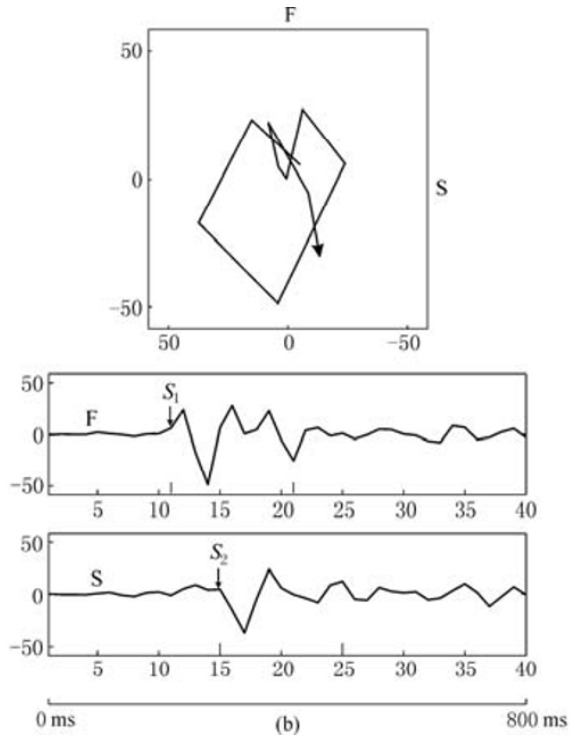

Figure 9 Check of polarization analysis of two peculiar waveforms

(a) Polarization of fast shear-wave is $75^{\circ}$ and time delay is $0.04 \mathrm{~s}$; (b) Polarization of fast shear-wave is $60^{\circ}$ and time delay is $0.08 \mathrm{~s}$. (a) and (b) in this figure correspond to the two earthquakes (a) and (b) in Figure 8, respectively. Other meanings in the figure are the same as in that Figure 4

The upper and middle diagrams are temporal variation of time delays ( $\Delta t-t$ diagram), the curve is the result of five-point fitting, and the oblique line is the result of beeline fitting. Ordinate is time delays, unit is $\mathrm{ms} / \mathrm{km}$; abscissa is time, unit is year and month. The lower diagram is the time distribution of earthquake magnitude within $60 \mathrm{~km}$ of station YK (M-t diagram), earthquake catalog is from Earthquake Administration of Liaoning Province, $M_{\mathrm{S}} 5.9$ in the diagram is the main shock of Xiuyan earthquake, and the result is from China Earthquake Networks Center. 
Table 1 Shear-wave splitting parameters for station YK (Yingkou)

\begin{tabular}{|c|c|c|c|c|c|c|c|c|}
\hline \multirow{2}{*}{ Station } & \multirow{2}{*}{$\begin{array}{l}\text { Station } \\
\text { code }\end{array}$} & \multirow{2}{*}{$\lambda_{\mathrm{E}} /^{\circ}$} & \multirow{2}{*}{$\varphi_{\mathrm{N}} /^{\circ}$} & \multicolumn{3}{|c|}{$\begin{array}{l}\text { Results of shear-wave splitting } \\
\text { (within shear-wave window) }\end{array}$} & \multicolumn{2}{|c|}{$\begin{array}{l}\text { Results of shear-wave splitting } \\
\text { (supplement data within } 8 \mathrm{~km} \text { ) }\end{array}$} \\
\hline & & & & $\begin{array}{l}\text { Record } \\
\text { number }\end{array}$ & $\begin{array}{l}\text { Polarization } \\
\text { direction }{ }^{\circ}\end{array}$ & $\begin{array}{l}\text { Time delay } \\
/ \mathrm{ms} \cdot \mathrm{km}^{-1}\end{array}$ & $\begin{array}{l}\text { Record } \\
\text { number }\end{array}$ & $\begin{array}{l}\text { Polarization } \\
\text { direction }{ }^{\circ}\end{array}$ \\
\hline Yingkou & YK & 122.60 & 40.68 & 131 & $76.1 \pm 26.2$ & $3.02 \pm 1.84$ & 143 & $75.9 \pm 25.3$ \\
\hline
\end{tabular}

Note: Polarization direction is the polarization of fast shear-wave, time delay is the normalized time delay of slow-shear wave.
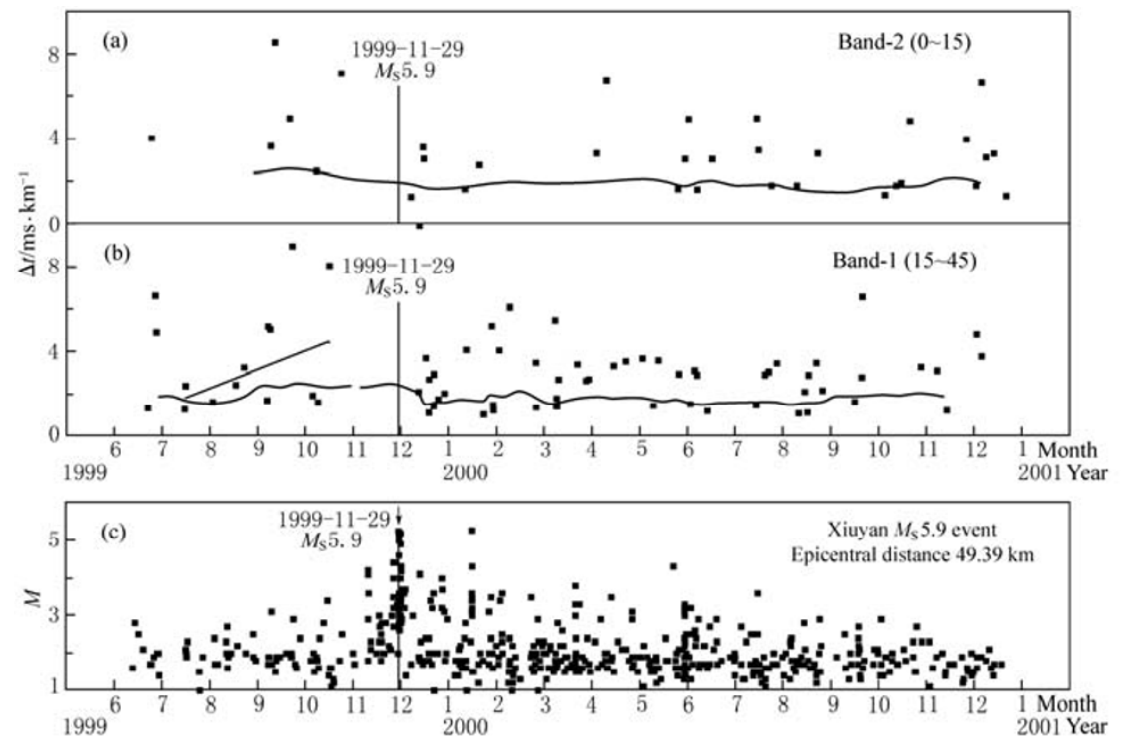

Figure 10 Variation of time delays recorded at station YK

(a) and (b) show variation of the time delay, the curve is the result of five-point fitting, and the oblique line comes from straight line fitting. Ordinate stands for time delay with unit of $\mathrm{ms} / \mathrm{km}$, and abscissa represents time in year and month. (c) shows the time variation of earthquake magnitudes for the quakes within $60 \mathrm{~km}$ from station YK. Earthquake catalog is taken from Earthquake Administration of Liaoning Province, but the parameters of main shock and the largest aftershock of Xiuyan earthquake sequence are determined by China Earthquake Network Center

Temporal variation of time delays $(\Delta t)$ and time distribution of earthquake magnitude within $60 \mathrm{~km}$ of station YK are shown in Figure 10. Band-1 is the double-leafed solid angle of ray paths between $15^{\circ} \sim 45^{\circ}$, time delays in this ray zone are more sensitive to the variation of cracks aspect ratio; time delays in band-2, ray paths within the solid angel $\pm 15^{\circ}$, are more sensitive to cracks density (Crampin, 1999). It is visible in the $\Delta t-t$ diagram that, time delays in band-1 gradually increase from July 1999 to October 1999 (the oblique line is the result of beeline fitting), this phenomenon verified again the stress increase before earthquake. However, because of lack of data within shear-wave window in November 1999, there is no possibility to analyze the data in this month; it results in no chance to observe the stress relaxation before earthquake (Gao and Crampin, 2004).

In order to statistically analyze the variation pattern of time delays before and after earthquake, the whole data are divided into four time stages in this study; the average $\Delta t$ is calculated in each time stage (Table 2). It is found that the average time delay is the highest before main shock and decreases after main shock (Figure 11). This phenomenon in general corresponds to the stress accumulation before earthquake and the decrease of $\Delta t$ may be influenced by stress relaxation af- 
ter main shock. While, the increase of average $\Delta t$ in three time stages after main shock is in the error range if considering the factor of standard error. The asymmetric time stage partition and data distribution of statistic sampling may result in statistic feint. However, it is obvious in Figure 11 that time delays are influenced by stress accumulation and stress relaxation before and after the earthquake, and the parameter $\Delta t$ can reflect the variation of stress.

Table 2 Average time delays of different time stages at station YK

\begin{tabular}{lc}
\hline \multicolumn{1}{c}{ Time stages } & Average time delay $/ \mathrm{ms}^{\circ} \mathrm{km}^{-1}$ \\
\hline Before main shock ( June 1999 to October 1999) & $3.88 \pm 2.47$ \\
After main shock to before the largest aftershock (December 1999 to 8 January 2000) & $2.61 \pm 1.93$ \\
After the largest aftershock to the end of sequence (16 January 2000 to October 2000) & $2.81 \pm 1.49$ \\
After the sequence (November 2000 to December 2000) & $3.12 \pm 1.56$ \\
\hline
\end{tabular}

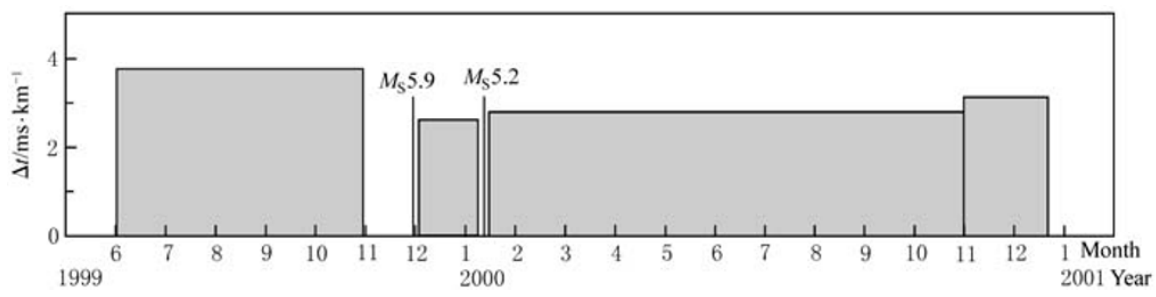

Figure 11 Average time delays of different time stages for station YK

$M_{\mathrm{S}} 5.9$ marks main shock of the Xiuyan earthquake sequence on 29 November, 1999, $M_{\mathrm{S}} 5.2$ denotes the largest 12 January, 2000 aftershock after the Xiuyan main shock. $M_{\mathrm{S}} 5.2\left(M_{\mathrm{L}} 5.4\right)$ is measured by China Earthquake Networks Center

CAO et al (2005) analyzed shear-wave splitting of Xiuyan earthquake sequence with 26 waveform data recorded at station YK from November 1999 to December 1999 and concluded that the average polarization of fast shear-waves is $\mathrm{N} 58.7^{\circ} \mathrm{E}$, polarizations of fast shear-waves after main shock are $\mathrm{N} 1{ }^{\circ} \mathrm{E} \sim \mathrm{N} 68^{\circ} \mathrm{E}$, average time delay is respectively $4.23 \mathrm{~ms} / \mathrm{km}$ for all data, 4.43 $\mathrm{ms} / \mathrm{km}$ before main shock and $4.15 \mathrm{~ms} / \mathrm{km}$ after main shock. However, the result of CAO et al (2005) is based on the data of extended shear-wave window; it depresses the reliability of the result. It is possibly also the primary reason for different result between these two studies.

Figure 12 is the equal-area project rose diagram of polarizations of fast shear-waves at station YK. Station YK locates at east of the Haicheng-Yingkou active fault, which strikes to NE, and there are NNE striking Jinzhou fault and NW striking Haichenghe fault around station YK (Figure 1). Comparing Figure 12a and 12b, the polarizations of more supplement data with epicentral distance less than $8 \mathrm{~km}$ is consistent with the polarizations of the data within shear-wave window. Therefore, when lack of data with focal depth, it is a way to add the data near station as supplement data according to the feature of the focal depth distribution to increase the reliability of analysis result of fast shear-wave polarization. This conclusion is consistent with SHI et al (2006). It can be seen from Figures 12a and 12b, the predominant polarizations of fast shear-waves strikes to ENE-WSW at station YK, it is consistent with the direction of the local principal compressive stress by ZHANG and JIANG (2001) and ZHANG et al (2001) with focal-mechanism solution, and also consistent with the direction of regional tectonic stress field in north part of North China, which strikes to nearly E-W. While, there are several records showing polarizations in NW-SE in Figures $12 \mathrm{a}$ and $12 \mathrm{~b}$, they may be influenced by the Haichenghe fault to east of the station. 
It is visible from histogram of monthly average polarizations of fast shear-waves at station YK (Figure 13) that polarizations of fast shear-waves also seem to change from two months before the earthquake. However due to lack of small earthquakes which could provide information, it is

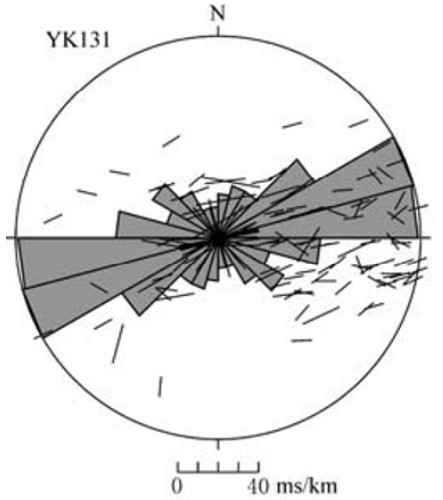

(a)

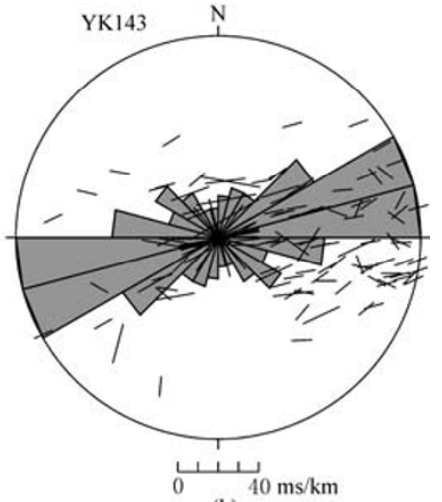

(b)

Figure 12 Equal-area project rose diagram of fast shear-wave polarization

(a) The analysis result of 131 records in shear-wave window at station YK; (b) The result of 143 records with additional data without focal depth determination, but with epicentral distance less than 8 $\mathrm{km}$ based on the Figure 12a. The short bars show fast shear-wave polarizations and the length of bar is proportional to the time delay. The scale below the rose diagram indicates the standard time delay.

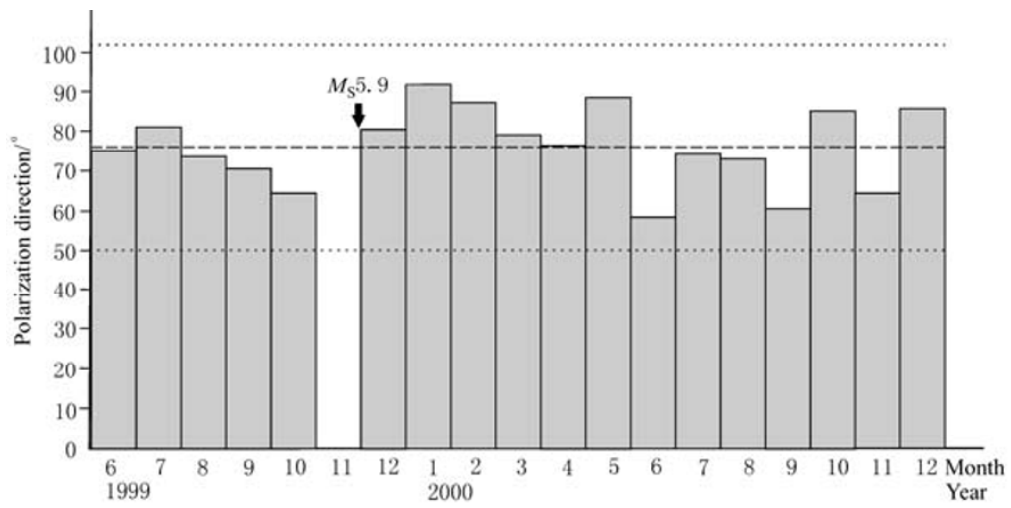

Figure 13 Histogram of monthly average polarizations of fast shear-waves for station YK $M_{\mathrm{S}} 5.9$ denotes main shock of Xiuyan earthquake sequence on November 29, 1999. Arrowhead shows the time of earthquake. The ordinate represents polarization azimuth in degree $\left({ }^{\circ}\right)$, and the abscissa denotes time in year and month

impossible to discuss here in detail. There are some researches on variation of the polarizations before and after earthquake and volcano (GAO and FENG, 1993; Gerst and Savage, 2004; Padhy and Crampin, 2006), but this phenomenon needs more data to verify.

\section{Discussion and conclusions}

This study analyzed the seismic data recorded at station YK of LTDSN from June 1999 to December 2000 with SAM method, researched the feature of shear-wave splitting before and after Xiuyan earthquake, and obtained the crustal anisotropy under station YK.

This study shows that the predominant polarization of fast shear-waves is consistent with the 
direction of local principal compressive stress and also consistent with the direction of the regional tectonic stress field in north part of North China. Several records polarized to NW-SE may be influenced by the Haichenghe fault striking NW.

The gestation and development of tectonic earthquake is actually with the process of stress accumulation, when the variation of stress field will change the rock feature in earthquake source region or around (ZHANG, 2002). However shear-wave splitting is very sensitive to the change of the cracks in the crust induced by the subtle change of the stress field. Research shows that shear-wave splitting parameters can reflect stress accumulation before earthquake and stress relaxation before impending earthquake (Gao and Crampin, 2004), this feature can be applied to earthquake forecasting (Crampin et al, 2003b). Earthquake development will induce the change of the cracks condition and this kind of tiny change can be measured by shear-wave splitting because shear-wave splitting observes cracks condition in the rock in the crust. Preparedness of large earthquake may change the stress condition of rocks in large range so that the stations which can reflect the change of stress during earthquake preparedness do not need definitely within the source region. Recent research suggested that it is possible to research the change of stress field on a $M_{\mathrm{L}} 3.5$ or $M_{\mathrm{L}} 4.0$ earthquake within $50 \mathrm{~km}$ (Crampin et al, 2003a).

By the seismic records at $\mathrm{YK}$, this study shows there is an increase period in time delays before Xiuyan earthquake; it shows stress accumulation before the earthquake (Figure 11). The increase is still obvious although lack of the data for one month before earthquake. The increase of time delays continued 142 days from the beginning of increase to occurrence of Xiuyan earthquake, it also accords with the relationship of duration of the increase of time delays and magnitudes obtained by Gao and Crampin (2006). However, the stress relaxation before earthquake cannot be obtained in this study because of lack of data before earthquake.

By having divided data into four time stages and calculated the average time delays in different time stages, this study finds that the average time delays for six months before Xiuyan earthquake are higher than the average time delays in other time stages after the main shock (Figure 11). This phenomenon may correspond to stress accumulation before earthquake and stress relaxation impending and after main shock, which reflects the process of stress change. The histogram of monthly average polarizations of fast shear-waves (Figure 13) shows that polarizations of fast shear-waves also seems to change from two months before the main shock, but it needs more data for verification.

Recent researches show that the predominant polarizations of fast shear-waves can be applied to estimating fault activity (SHI et al, 2006; WU et al, 2007). In this study, station YK is to east of Haicheng-Yingkou fault striking NE and at front of Jinzhou fault striking NE, which seems not directly to be on a large fault, but nearly E-W direction of spatial distribution of small earthquakes indicates a fault striking nearly E-W below station YK (Figure 1). This direction is consistent to the predominant polarization of fast shear-waves at $\mathrm{YK}$.

According to the research by SHI et al (2006), this paper further verifies that due to incomplete data service in China it is acceptable to adopt data without focal depth determination but close to the station, for example, epicentral distance less than $8 \mathrm{~km}$, to improve the reliability of shear-wave splitting analysis.

\section{References}

CAO Feng-juan, WANG Lian-quan, ZHANG Ping, et al. 2005. Study on S-wave fission around Xiuyan $M_{\mathrm{S}} 5.4$ earthquake [J]. Seismological Research of Northeast China, 21(4): 39-44 (in Chinese). 
Crampin S and Atkinson B K. 1985. Microcracks in the earth's crust [J]. First Break, 3(3): 16-20.

Crampin S and Peacock S. 2005. A review of shear-wave splitting in the compliant crack-critical anisotropic Earth [J]. Wave Motion, 41: $59-77$.

Crampin S, Chastin S, Gao Y. 2003a. Shear-wave splitting in a critical crust (III): Preliminary report of multi-variable measurements in active tectonics [J]. J Appl Geophys, 54: 265-277.

Crampin S, Gao Y, Chastin S, et al. 2003b. Speculations on earthquake forecasting [J]. Seism Res Lett, 74(3): 271-273.

Crampin S. 1999. Calculable fluid-rock interactions [J]. J Geol Soc Lond, 156: 501-514.

Crampin S. 2001. Developing stress-monitoring sites using cross-hole seismology to stress-forecast the times and magnitudes of future earthquakes [J]. Tectonophysics, 338: 233-245.

GAO Chang-bo and ZHONG Yi-zhang. 2000. Geological backguound and seismogenic fault of the Haicheng-Xiuyan M5.6 earthquake of November 29,1999 [J]. Seismology and Geology, 22(4): 405-412 (in Chinese).

Gao Y and Crampin S. 2004. Observations of stress relaxation before earthquakes [J]. Geophys J Int, 157(2): 578-582.

Gao Y and Crampin S. 2006. A further stress-forecast earthquake (with hindsight), where migration of source earthquakes causes anomalies in shear-wave polarizations [J]. Tectonophysics, 426(3/4): 253-262.

GAO Yuan and FENG De-yi. 1993. Observations and researches on local earthquake S-wave splitting of Datong region [J]. Acta Seismologica Sinica, 15(Suppl): 521-527 (in Chinese).

GAO Yuan and ZHENG Si-hua. 1994. On shear wave splitting in Tangshan region (II): Correlation function analysis method [J]. Earthquake Research in China, 10(Suppl): 11-21 (in Chinese).

GAO Yuan, LIU Xi-qiang, LIANG Wei, et al. 2004. Systematic analysis method of shear-wave splitting: SAM software system [J]. Earthquake Research in China, 20(1): 101-107 (in Chinese).

GAO Yuan, ZHENG Si-hau, SUN Yong. 1995. Crack-induced anisotropy in the crust from shear wave splitting observed in Tangshan region, North China [J]. Acta Seismologica Sinica, 8(3): 351-364.

GAO Yuan, ZHENG Si-hua, WANG Pei-de. 1996. Shear-wave splitting study on small earthquake swarm of 1992 in Dongfang of Hainan, south China [J]. Acta Geophysica Sinica, 39(2): 221-232 (in Chinese).

Gerst A and Savage M K. 2004. Seismic anisotropy beneath Ruapehu volcano: A possible eruption forecasting tool [J]. Science, 306(5701): 1 543-1 547.

JIANG Xiu-qin and TONG Xiao-hui. 2001. Synthetic description about Xiuyan-Haicheng, Liaoning earthquek with magnitude of $M_{\mathrm{S}} 5.4$ on November 29, 1999 [J]. Seismological and Geomagnetic Observation and Research, 22(2): 1-9 (in Chinese).

LAN Cong-xin, LIU Jie, MA Shi-zhen, et al. 2006. Study on stress variation characteristics of Xiuyan 5.4 earthquake series [J]. Earthquake, 26(2): 73-82 (in Chinese).

LÜ Pei-liang, YANG Zhi-xian, WANG Xiao-qing, et al. 2004. Investigation of the 1999 Xiuyan earthquake sequence, Liaoning Province, China [J]. Earthquake, 24(4): 45-50 (in Chinese).

MA Xing-yuan. 1989. Lithospheric Dynamic Atlas of China [M]. China Cartographic Publishing House, 32-33 (in Chinese).

Mizuno T, Ito H, Kuwahara Y, et al. 2005. Spatial variation of shear-wave splitting across an active fault and its implication for stress accumulation mechanism of inland earthquakes: The Atosugawa fault case [J]. Geophys Res Lett, 32: L20305, doi:10.1029/2005GL023875.

Padhy S and Crampin S. 2006. High pore-fluid pressures at Bhuj, inferred from $90^{\circ}$-flips in shear-wave polarizations [J]. Geophys $J$ Int, 164: 370-376.

SHI Yu-tao, GAO Yuan, WU Jing, et al. 2006. Seismic anisotropy of the crust in Yunnan, China: Polarizations of fast shear-waves [J]. Acta Seismologica Sinica, 19(6): 620-632.

Tang C, Rial J A, Lees J M. 2005. Shear-wave splitting: A diagnostic tool to monitor fluid pressure in geothermal fields [J]. Geophys Res Lett, 32: L21317, doi:10.1029/2005GL023551.

WAN Bo. 2000. Seismogeological features and seismogenic structure analysis of Haicheng-Xiuyan $M_{\mathrm{S}} 5.6$ earthquake [J]. Seismological Research of Northeast China, 16(2): 27-32 (in Chinese).

WU Jing, GAO Yuan, CHEN Yun-tai, et al. 2007. Seismic anisotropy in the crust in northwestern capital area of China [J]. Chinese $J$ Geophys, 50(1): 209-220 (in Chinese).

ZHANG Ping and JIANG Xiu-qin. 2001. Study of focal mechanism solutions and stress field characteristics in Liaoning region [J]. Seismological and Geomagnetic Observation and Research, 22(2): 76-82 (in Chinese).

ZHANG Ping, GU Guang-yu, GAO Yan-ling. 2001. The focal mechanism solutions and the crust stress field characteristics in Xiuyan-Haicheng $\left(M_{\mathrm{S}} 5.4\right)$ earthquake sequence [J]. Earthquake, 21(1): 98-101 (in Chinese).

ZHANG Zhong-jie. 2002. A review of the seismic anisotropy and its applications [J]. Process in Geophysics, 17(2): 281-293 (in Chinese). 